\title{
CONSOLIDAÇÃO DO DIREITO À MORADIA À LUZ DA LEI No 13.465/17: (IN)DISPENSABILIDADE DO MARCO LEGAL
}

\author{
CONSOLIDATION OF THE RIGHT TO ADEQUATE HOUSING IN VIEW OF THE \\ LAW No 13.465/17: (IN) DISPENSABILITY OF THE LEGAL FRAMEWORK
}

\author{
José Albenes Bezerra Júnior ${ }^{1}$ \\ Milena Santos Ferreira ${ }^{2}$
}

\begin{abstract}
RESUMO
O trabalho é voltado para a importância da regularização fundiária urbana de interesse social e sua relação com os institutos jurídicos que visam a efetividade do direito à moradia digna. $\mathrm{O}$ objetivo da pesquisa é avaliar se a aplicação da regularização fundiária de interesse social tem promovido a consolidação do direito à moradia, como fonte alternativa principalmente aos financiamentos habitacionais impulsionados pelo Governo Federal. Para isso, a pesquisa vai analisar os motivos pelos quais o regime procedimental da Lei $\mathrm{n}^{\circ} 11.977 / 09$ foi alterado e quais os benefícios ou malefícios que essa derrogação, pela Lei ${ }^{\circ}$ 13.465/17 (conversão da Medida Provisória $\mathrm{n}^{\mathrm{o}} 759 / 16$ ), trouxe ao ordenamento jurídico e ao contexto social. Para tanto, seguiuse os métodos de abordagem indutivo e dialético, os métodos de procedimento histórico e comparativo e foi utilizada a metodologia quali-quantitativa.
\end{abstract}

Palavras-chave: Direito social; Doação de propriedade; Moradia; Legitimação de posse; Regularização fundiária.

\begin{abstract}
The study aims at the importance of land regularization of social interest and its proceedings with legal institutions that focus on the effectiveness of the right to adequate housing. The research targets to evaluate whether the application of land regularization of social interest has promoted consolidation to adequate housing, as an alternative path mainly to housing loans impelled by the Federal Government, to examine the reasons why the procedural regime of the Law $\mathrm{n}^{\circ} 11.977 / 09$ has been altered and the benefits or disadvantages that this derogation, by the Law $n^{\circ} 13.465 / 17$ (conversion of the interim measure $n^{\circ} 759 / 16$ ), has brought to the legal order and social context. For that, were followed the methods of inductive and dialectical approach,

\footnotetext{
${ }^{1}$ Graduado em Direito pela Universidade de Fortaleza, UNIFOR. Mestre em Direito pela Universidade Federal do Rio Grande do Norte, UFRN. Doutor em Direito pela Universidade de Brasília, UnB. Professor da Universidade Federal Rural do Semiárido, UFERSA. Afiliação: Universidade Federal Rural do Semiárido - UFERSA. Rio Grande do Norte. Lattes:http://lattes.cnpq.br/8595449661860162 ORCID: https://orcid.org/0000-0002-7598-8856 e-mail:albenes.junior@ufersa.edu.br

${ }^{2}$ Graduada em Direito pela Universidade Federal Rural do Semiárido, UFERSA. Afiliação: Universidade Federal Rural do Semiárido - UFERSA. Rio Grande do Norte. Lattes:http://lattes.cnpq.br/4790362470014142. email:smilena14@gmail.com
} 
the methods of historical and comparative procedure and the quantitative and qualitative methodology.

Keywords: Social law; Donation of property; Home; Legitimation of possession; Land regularization.

\section{INTRODUÇÃO}

O direito à moradia digna é a porta de entrada para a cidadania e para a consecução de muitos direitos expressos na Constituição Federal Brasileira. Sob essa perspectiva, convém compreender a regularização fundiária urbana de interesse social, já que introduzida na ordem jurídica do país recentemente e substituída pela Lei n n 13.465/17.

Levando-se em consideração a suma importância dos fenômenos históricos e sociais, assim como a autoridade do tema, pela forma constante, influência e valoração em que se apresenta na sociedade brasileira, o trabalho então inicia-se com breve análise histórica acerca do direito de propriedade, partindo, em seguida, para um ponto bastante pertinente no que diz respeito aos instrumentos jurídicos aplicáveis para a referida regularização.

Após a apreciação do procedimento de regularização fundiária urbana de interesse social no País, descrito na Lei n ${ }^{\circ}$ 11.977/09, serão citados os dados colhidos com o Programa Acesso à Terra Urbanizada como um contraponto empírico.

Ao final, os resultados obtidos com o projeto de extensão serão associados com os motivos alegados pelo Governo Federal para a alteração do anterior marco legal e serão examinadas as principais alterações que o novo procedimento trouxe; só então será manifesto se a Lei no 13.465/17, em relação à regularização fundiária urbana de interesse social, é benéfica, tanto sob o contexto socialmente conturbado que envolve as questões fundiárias quanto em relação ao ordenamento jurídico, isto é, a sua possível inconstitucionalidade material e se é oposta aos outros marcos regulatórios.

Ainda, será mencionada a teoria da escolha pública, revisada pelo jurista norteamericano Steven Croley, professor de Direito Administrativo na Universidade de Michigan Law School, que defende o Estado regulador e analisa a função dos procedimentos administrativos para um boa governança.

A relevância do presente estudo para a ciência jurídica decorre, portanto, da revisão e da consolidação dos instrumentos pertinentes, o qual viabilizará, através de uma investigação imparcial sobre a nova regulamentação, baseada em experiência de campo, uma conclusão 
estável a respeito da (in)dispensabilidade da substituição do procedimento previsto na Lei ${ }^{\circ}$ $11.977 / 09$.

Ao término deste estudo serão manifestos os fatores da trajetória histórica e social que identificam e delimitam as características do direito à moradia na República Federativa do Brasil, alguns dados empíricos recentes e os instrumentos jurídicos da regularização fundiária urbana de interesse social, notadamente a legitimação de posse, formando, ao fim, uma base interpretativa sólida e válida para os resultados que serão revelados sobre a perspectiva de efetividade do direito constitucional à moradia segundo a aplicação da Lei no 13.465/17.

\section{ANÁLISE HISTÓRICO-SOCIAL DO DIREITO À PROPRIEDADE}

\subsection{Notas acerca da evolução do direito de propriedade}

Ao se reconhecer como parâmetro a herança greco-romana nos ordenamentos jurídicos ocidentais, é salutar compreender, pela dimensão histórico-social até então apreendida pelo homem, o caráter perpétuo e sagrado da propriedade das famílias à época das antigas cidades, em especial da Grécia e de Roma (COULANGES, 2016, p. 73).

Apenas com o passar do tempo é que são traçadas, gradativamente, algumas restrições à sua plenitude de uso, gozo, reivindicação e sucessão, das quais cabe citar, especialmente, a partilha realizada em cerimônia sacerdotal, a evolução dos direitos de vizinhança e a diminuição dos poderes dos senhores sobre os seus escravos.

Foi em Roma que surgiu a propriedade juridicamente permissiva quanto ao domínio e ao uso, de modo que o seu dono usufruísse da terra como lhe aprouvesse, com amparo normativo nas Leis das XII Tábuas, consoante explanação de Antiqueira (2017, p. 11):

Ao reconhecer a faculdade testamentária de um paterfamilias (Lex XII Tab. V, 3), a Lei das XII Tábuas permitiu que um homem dispusesse de seu patrimônio da maneira que lhe conviesse. Neste sentido, o poder estatal reconhecia e protegia, assim, a propriedade privada. O primogênito deixou de ser o herdeiro necessário, como as antigas prescrições religiosas postulavam, visando à inalienabilidade da propriedade e a transmissão do culto familiar. Apenas as sucessões $a b$ intestado, ou seja, na ausência de testamento, seguiriam o antigo procedimento (Lex XII Tab. V, 4), em que os bens eram legados aos herdeiros que integravam a domus do falecido pater, denominados sui heredes.

Depois da queda do Império Romano e o surgimento do Sistema Feudal (Idade Média), a propriedade passa a ser considerada de maneira totalmente diversa, da qual se distinguem domínio e uso, ou posse indireta e direta: os proprietários eram os senhores dos feudos, com 
direitos sobre a terra e sobre a cobrança de tributos pelo território, e os vassalos contribuíam com o trabalho servil, morando nos feudos em troca de proteção e alimento.

Nesse sentido, os valores de uso da terra basearam-se numa nova conjuntura histórica e econômica, a saber, de uma produção de subsistência essencialmente agrária (BLOCH, 2009, p. 188).

Inclusive, atente-se para a observação de que essa sistemática de direito real tem especial afinidade com o instituto, muito conhecido, da enfiteuse, originária do direito romano, mas que tomou relevo ímpar neste período medieval (CHAVES; ROSENVALD, 2015, p. 661).

$\mathrm{O}$ tratamento dado à questão da propriedade foi novamente modificado com o ressurgimento do comércio e das cidades, além da centralização política que caracterizaram a Idade Moderna, marcada pelo Absolutismo.

Dessa época, a ideia de concentração política e econômica era considerada necessária e justa, e até mesmo adotada por filósofos de então, como Nicolau Maquiavel - que, em seu $O$ Príncipe (1532), forneceu conselhos sobre a arte de governar, justificando atos de crueldade e violência desde que pudessem por fim gerar a ordem e sua manutenção. De seu livro, certo trecho é nesse sentido (2010, p. 102):

[...] se um príncipe quiser manter o poder, muitas vezes será forçado a não ser bom. Pois, quando uma das forças - povo ou soldados ou poderosos que sejam - de cujo apoio o príncipe acredita depender para manter-se é corrupta, convém que ele siga o humor dela a fim de contentá-la, e nesse caso as boas ações lhe serão prejudiciais.

Reforce-se, por seu turno, que o pensamento liberal igualmente contribuiu para a reformulação do conceito de propriedade como um direito absoluto, subjetivo e essencialmente natural e inalienável: John Locke (2005, p. 407-410), expoente de seu tempo, fundamentou que a propriedade já existia na natureza antes mesmo do surgimento das sociedades e do Estado, pois base do governo civil, de forma que a este não seria possível intervir no exercício desse direito.

Mais tarde, vê-se que com a tranformação do processo histórico, de significativas mudanças sociais, políticas e institucionais, tais como as que se evidenciam em virtude da Primeira Guerra Mundial (1914-1919), da Revolução Russa (1917), da Constituição de Weimar (1919) e da Constituição Mexicana de 1917, passou a ser adotado um modelo de proteção estatal em relação à educação, à saúde, à alimentação, ao trabalho, à moradia, entre outros, gerando o que comumente passou a ser chamado de Estado Social. 
Exemplo cristalino dessa constatação é a Declaração Universal dos Direitos Humanos (DUDH), proclamada pela Resolução n 217-A (III) da Assembléia Geral das Nações Unidas, em 1948, e assinada pelo Brasil no mesmo ano.

É agora no Estado Democrático e Social de Direito - uma evolução do Estado de Direito - que sobrevêm a função social, como é adotada atualmente, e diversas outras restrições que condicionaram, como imposição constitucional, saliente-se, o domínio e o uso da terra.

Sobre as origens da propriedade, no Brasil, é fundamental mencionar a sesmaria. Esse instituto jurídico, de origem portuguesa, está de tal modo enraizado no sistema econômico e cultural brasileiro que até os dias de hoje compõe a problemática da propriedade territorial.

Sabe-se que a norma correspondente, por ordem da Coroa, introduziu o sistema de sesmarias em um contexto basicamente escravagista e monocultor, com a finalidade de estimular a produção de alimentos e proteger o domínio português, que consistia na concessão de uso condicionado ao cultivo do solo; aí o que na prática se confirmou como plantation latifúndios nos quais se produziam cana-de-açúcar em larga escala (FAUSTO, 1995, p. 48).

O que ocorreu em terras brasileiras, contudo, acabou por ser um procedimento diverso do que foi aplicado em Portugal, de maneira tal que as concessões se deram de forma permanente, servindo, ao fim, para os interesses metropolitanos em conservar o domínio e o uso da propriedade para aqueles, e suas famílias, que efetivaram a economia de plantation.

Ainda, para a compreensão da propriedade e seu direito a ela em terras brasileiras, imprescindível é a análise acerca da Lei $\mathrm{n}^{\circ}$ 601, de 1850, ou como ficou conhecida: a Lei de Terras. Através desse documento legal, já à época do Império, criou-se uma nova política com a abolição do antigo sistema de sesmarias e com a permissão de compra à vista (art. $1^{\text {o: }}$ "Ficam prohibidas as acquisições de terras devolutas por outro titulo que não seja o de compra.” [sic]).

Isto possibilitou (sem esquecer o debate posterior acerca da adoção gradual do trabalho livre de imigrantes, sobretudo italianos e japoneses), a regularidade territorial e a manutenção dos interesses dos grandes proprietários de lavouras de café, no novo século (FAUSTO, 1995, p. 48). Destarte, não mais haveria autorização de concessões de domínio sob o fundamento da posse.

Já seguindo as bases estabelecidas pelas constituições brasileiras, observe-se que é tão somente em 1934 que advêm as figuras da coletividade e do interesse social sobre o direito de propriedade (art. 113, item 17). 
Até então esse direito foi estabelecido e respeitado sem restrições, visto que era definido de forma genérica, a conferir a plenitude do exercício de propriedade, pelas constituições de 1824 (art. 179, inciso XXII) e 1891 (art. 72, § 17), que foram, respectivamente, outorgada e promulgada sob influência das revoluções liberais.

\subsection{O direito fundamental e a dignidade da pessoa humana}

Feitas todas essas premissas históricas, torna-se mais fácil depreender que o direito de propriedade, atualmente, condiciona a individualidade natural de seu exercício, visto que decorre de um bem que pressupõe domínio e/ou uso, à coletividade.

É com a finalidade que se apresenta em atingir a coletividade, bem como a organização e a mediação das disputas de terras, que a função social surge como elemento regulamentador do direito de propriedade e garantidor legal do direito à moradia, este que se formaliza como direito social que salvaguarda os hipossuficientes.

Segundo redação dada pela EC n ${ }^{\circ} 90 / 2015$, o art. $6^{\circ}$ da atual Carta Magna prescreve um rol de direitos sociais, entre os quais a moradia. Diante do exposto, ao direito à moradia, positivado como direito fundamental, e em cotejo com os demais direitos elencados no referido artigo, foi acrescentado o benefício de que ela deve ser digna, proporcionando conforto e proteção (SILVA, 2007, p. 314).

Nesse contexto, a concretização do direito à moradia suscita a "materizalização" da dignidade da pessoa humana (fundamento da República Federativa do Brasil - art. $1^{\circ}$, inciso III da $\mathrm{CF} / 88$ ), de maneira que não importa por qual se argumente - pela dignidade ou pela moradia -, ambas são meios e fins. A sua proteção estatal, contudo, representa mera formalidade sem os correspondentes meios de efetivação.

É oportuno recordar que o Direito Internacional, na forma dos tratados em sua grande maioria de Direitos Humanos, após sua incorporação ao ordenamento nacional, é juridicamente suficiente para corrigir a deficiência social aqui analisada (MAZZUOLI, 2011, p. 223).

Dentre os quais, citem-se novamente a Declaração Universal de Direitos Humanos, de 1948 (em especial seu art. XXV, n. 01) e o Pacto Internacional sobre Direitos Econômicos, Sociais e Culturais (Decreto $n^{\circ}$ 591/92, art. 11, n. 01). 
Ainda prevalece a concepção de que as mazelas sociais são sanadas com o máximo de produção legislativa possível, dedicando-se o parlamento a produzir normas até mesmo desnecessárias ante a total proteção constitucional.

Essa tutela por si só já possui significativa ordem mandamental (SARLET, 2007, p. 29), sobretudo pela influência do princípio da força normativa da constituição, apontado por Konrad Hesse, que se sobressai de acordo com o dinamismo da realidade jurídica, social e política de uma sociedade.

Ainda assim, o déficit habitacional de dimensão em torno de 6,2 (seis vírgula dois) milhões de moradias $^{3}$ revela preocupante situação de desrespeito aos principais fundamentos normativos acima indicados.

Aliás, a questão habitacional não se restringe a uma ausência ou falta, visto que também é demonstrada pela frágil condição de habitabilidade. Assim é, pois, pela perspectiva da moradia digna, e não somente através da construção e financiamento das chamadas "casas populares" sem o rigor qualitativo necessário aos beneficiados, como já ocorreu com o Programa de Arrendamento Residencial (PAR) em alguns estados brasileiros, tal como o Rio de Janeiro, no Conjunto Habitacional Lívia Pinto Teixeira.

A demanda habitacional retromencionada inviabiliza o desenvolvimento nacional, apesar do crescimento urbano, e tome-se como exemplo um clássico da literatura nacional: demonstrando o que ocorria na cidade do Rio de Janeiro já no final do século XIX, Aluísio Azevedo retratou com maestria o processo de urbanização em sua obra $O$ Cortiço (1890), ao descrever a exploração de uma região descentralizada e marginal do espaço urbano.

É de se concluir, portanto, que a carência de moradia adequada aos cidadãos de baixa ou nenhuma renda ainda é um problema crônico conjuntural da realidade nacional, pois as políticas públicas existentes concentram-se num público beneficiário de renda mensal média, propiciando incipientes melhorias, em que pese movimentar a economia com a geração de empregos no setores de engenharia e construção, que favoreceu o país na crise econômica de meados de 2008 .

Em que pese a existência de todo um histórico legislativo e também vários planejamentos de índole administrativa, bem como a ponderação exercida pelos órgãos

\footnotetext{
${ }^{3}$ Dados estatísticos elaborados pelo Centro de Estatística e Informação (CEI) da Fundação João Pinheiro (FJP), em parceria com o Ministério das Cidades, Banco Interamericano de Desenvolvimento (BID) e Programa das Nações Unidas para o Desenvolvimento (PNUD), com base nas informações colhidas pela Pesquisa Nacional por Amostra de Domicílios (PNAD) do IBGE (Instituto Brasileiro de Geografia e Estatística), v. 34, 2014.
} 
jurisdicionais, a realidade social tem revelado, em verdade, uma preocupante situação de desrespeito à dignidade humana.

Diante dessa conjuntura, por fim, foi editada a Lei $\mathrm{n}^{\circ} 11.977 / 09$, marco normativo divisor de águas, nesta seara, em toda a história do ordenamento jurídico brasileiro, pois inovou, complementou e considerou conceitos multidisciplinares a respeito da moradia digna, do acesso à cidade, de procedimentos complexos, abrangendo a atividade legiferante dos municípios, das associações civis, do auxílio notarial e registral, do acompanhamento pelo Poder Público, dentre outros, que serão analisados a seguir.

Neste cenário, vislumbra-se a recente alteração do sistema de regularização fundiária com a edição da Medida Provisória nº 759/2016 e a sua conversão na Lei nº 13.465/2017.

\section{INSTRUMENTOS JURÍDICOS PERTINENTES À IRREGULARIDADE DOMINIAL}

Preliminarmente, urge mencionar a regularização fundiária urbana de interesse social como um processo ${ }^{4}$ orientado por lei para solucionar, através de mecanismos jurídicos, urbanísticos, ambientais e sociais, uma situação habitacional à margem da lei, em assentamento popular.

Antes de iniciar a análise acerca das alterações trazidas pela nova sistemática, é imperioso descrever, a título de compreensão basilar e a fim de circunscrever as razões e as críticas à recente legislação (Lei no 13.465/17), a maneira pela qual até então, na prática, se estabelecia a regularização fundiária, guiada essencialmente pelos comandos da Lei $\mathrm{n}^{\mathbf{o}}$ $11.977 / 09$.

O procedimento de regularização fundiária urbana de interesse social, de natureza complexa, por envolver diversos agentes da Administração Pública e da sociedade, se inicia com a fase de demarcação urbanística, que, como a sua denominação indica, se refere à delimitação do imóvel, seja público ou privado, para identificar os ocupantes e qualificar a natureza e o tempo de sua posse (consoante redação do antigo art. 47, inciso III, da Lei $\mathrm{n}^{\circ}$ $11.977 / 09)$.

Em outras palavras, o levantamento da área requer uma pesquisa fundiária que abrange aspectos topográficos, socioeconômicos - a esclarecer o perfil da população a ser beneficiada

\footnotetext{
${ }^{4}$ Segundo Celso Antônio Bandeira de Mello, procedimento ou processo administrativo é uma sucessão de atos administrativos com vistas a um resultado final (in Curso de Direito Administrativo, 2013, p. 495).
} 
- e jurídicos - a permitir uma verificação acerca da legislação municipal existente a respeito, tais como plano diretor, código de obras e código de postura, bem como quanto à condição de registro do(s) bem(ns) nos cartórios extrajudiciais locais.

É tão somente com os dados resultantes desta ampla diligência, isto é, de histórico da terra e delimitação de características sociais, que será possível considerar a viabilidade do procedimento de regularização.

Com esta etapa finda, o Poder Público (no caso, União, Estado, Distrito Federal ou Município) lavrará o Auto de Demarcação Urbanística, o qual deverá ser instruído com plantas, memoriais descritivos e certidão de matrícula do imóvel/assentamento irregular.

O auto, então, será enviado ao Cartório de Registro de Imóveis respectivo, oportunidade em que, antes de averbá-lo, o oficial cartorário deverá notificar o proprietário, os confrontantes e eventuais interessados para que, sendo o caso, apresentem impugnação à averbação.

Havendo impugnação total da área, mesmo após tentativa de acordo, o procedimento não mais terá continuidade; porém, não sendo assim, ocorrerá a averbação do auto de demarcação urbanística na matrícula do imóvel (se não houver, ou se o bem abranger mais de uma, a regra é que se proceda à abertura de uma nova matrícula).

A fase seguinte é o projeto de regularização fundiária elaborado pelo ente responsável (seja a União, o Estado ou o Município, conforme explanação anterior). É nesse momento que serão utilizadas as informações colhidas nas primeiras pesquisas.

Em consequência, munido de todos os documentos de referências quantitativas e qualitativas (tais como as edificações existentes, a viabilidade urbanística e ambiental, em obediência aos parâmetros estabelecidos no Estatuto da Cidade e leis municipais), o Poder Público promoverá o cadastramento socieconômico dos possuidores e elaborará uma planta de parcelamento da área.

Em seguida, o projeto de regularização fundiária será submetido à análise do Município, que o aprovará, com a concessão do licenciamento urbanístico e ambiental, se respeitadas todas as condições legais. Aprovado o projeto, dar-se-á o seu prosseguimento com o registro, em cartório, do parcelamento e, por conseguinte, de abertura de novas matrículas para cada lote.

Como o cadastramento socioeconômico fora feito anteriormente, antes do parcelamento do solo, caberá ao Poder Público, tão somente, superada toda a jornada procedimental acima descrita, conceder o título de legitimação de posse (que nada mais é que o reconhecimento da 
posse, pelos órgãos estatais) àqueles cadastrados, o qual também deverá ser averbado na matrícula do lote.

O recebimento do título de legitimação de posse será condicionado apenas aos que, dentre os ocupantes, possivelmente beneficiários, não forem concessionários, foreiros ou proprietários de outro imóvel (urbano ou rural), ou ainda que não tenham recebido título semelhante em outra ocasião.

Por fim, após o decurso de cinco anos do registro do título de legitimação de posse, poderá o possuidor requerer, junto ao cartório extrajudicial respectivo, a conversão do título de posse em título de propriedade, em virtude da aquisição mediante usucapião administrativa, na forma da previsão contida no art. 183 da Constituição Federal.

Logo, é de se constatar, ao menos diante destas prescrições legais, que a regularização fundiária urbana de interesse social, além de se prestar a garantir o direito fundamental objeto do presente estudo, seja pelo ponto de vista socioeconômico, urbanístico ou ambiental, trazendo segurança jurídica ao exercício de posse, também é meio eficaz, para o poder estatal, de controle, fiscalização e recolhimento de tributos afetos ao bem imóvel.

Traçado todo o procedimento de regularização, é fundamental expor as referências do contexto prático, o que assenta bem com a menção aos dados obtidos pelo Programa Acesso à Terra Urbanizada, estabelecido pela UFERSA (Universidade Federal Rural do Semiárido) em parceria com o Ministério da Educação (MEC) e o Ministério das Cidades (MCidades), no Estado do Rio Grande do Norte, no ano de 2015.

Este projeto de pesquisa e extensão, que possibilitou a atuação docente e discente através de uma seleta equipe proveniente das quatro áreas de conhecimento essenciais à regularização fundiária de interesse social (direito, topografia, engenharia civil e serviço social), operou em onze muncípios do interior potiguar, a saber: Assu, Carnaubais, Encanto, Governador Dix-Sept Rosado, Janduís, Luís Gomes, Pau dos Ferros, Portalegre, São Miguel, Tibau e Venha-Ver.

Destes, aproveita ao estudo colher apenas algumas amostras obtidas mediante pesquisa de campo. No município de Governador Dix-Sept Rosado, por exemplo, constatou-se a existência de seis assentamentos urbanos informais (conjuntos): Projeto Crescer (área 1), José Freire do Vale (área 2), Campestre (área 3), Fausto Martins (área 4), Dix-Huit Rosado (área 5) e Liberato Lopes (área 6), totalizando oitocentas e dez moradias. 


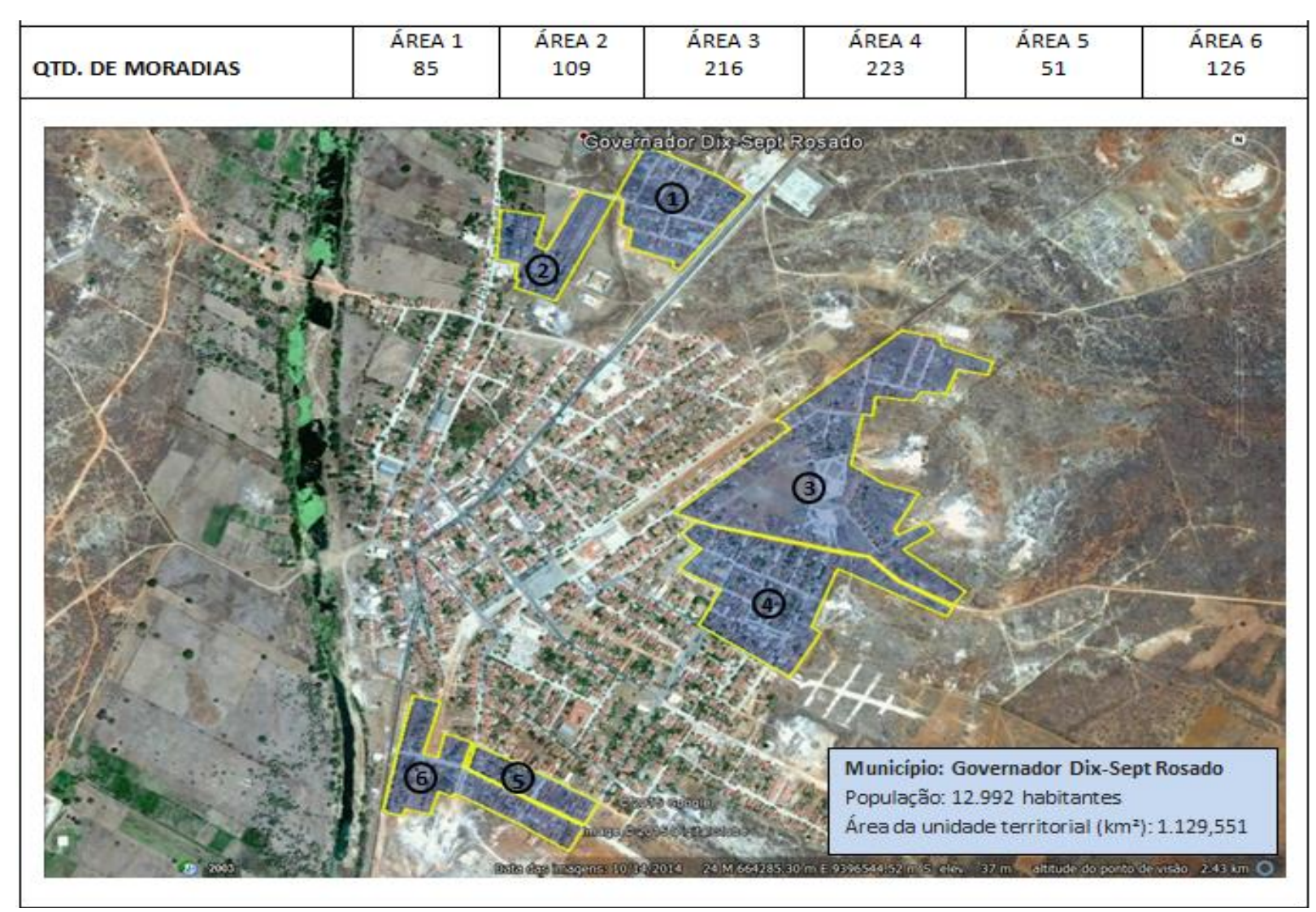

Figura 1 - Planta de identificação dos assentamentos informais de Governador DixSept Rosado/RN

Fonte: Programa Acesso à Terra Urbanizada, 2015.

Sobre a atuação legiferante deste município e a situação jurídica dos conjuntos habitacionais irregulares, foram coletadas as seguintes informações:

\begin{tabular}{l} 
INSTRUMENTOS JURÍDICOS E URBANÍSTICOS DISPONÍVEIS NO MUNICíPIO \\
\hline Os instrumentos jurídicos e urbanísticos presentes no município de Governador Dix-Sept Rosado são: \\
- Lei de delimitação do perímetro urbano (Lei no 432/2011, de 22 de Agosto de 2011); \\
- Código Tributário (Lei no 083, de 31 de dezembro de 1990); \\
- Lei de Doação de Terrenos, que institui o Programa "UM CHÃO PARA TODOS", o qual consiste na doação de \\
terrenos pertencentes ao patrimônio público, destinados à construção residencial a pessoas e/ou famílias \\
comprovadamente necessitadas e que não possuam residência própria (Lei no 412/2007, de 29 de novembro de \\
2007); \\
- Lei que autoriza o Poder Executivo Municipal a desenvolver ações para implementar do Programa Minha Casa \\
- Linha vida - PMCMV - Lei no $11.977 / 09$, de 07 de Julho de 2009 - (Lei no $409 / 2010$ de 29/04/2010); \\
providências (Lei no $392 / 2009$, de 04 de Junho de 2009); \\
- Lei que autoriza o Poder Executivo Municipal a desenvolver ações para implementar o Programa de Subsídio à \\
Habitação de Interesse Social - PSH (Lei no $391 / 2009$, de 04 de Junho de 2009).
\end{tabular}


Figura 2 - Relação de instrumentos jurídicos disponíveis em Governador Dix-Sept Rosado/RN

Fonte: Programa Acesso à Terra Urbanizada, 2015

\section{OBSERVAÇÕES}

- O Município de Governador Dix-Sept Rosado não possui Plano Diretor e Zonas Especiais de Interesse Social (ZEIS);

- Nenhuma unidade habitacional localizada nos assentamentos visitados possui registro de imóveis (doações, concessão de posse, usucapião, escritura pública, etc.). Segundo relato da Tabeliã, as Escrituras Públicas referentes às matrículas mães encontradas estão em posse do Município.

- No Conjunto José Freire do Vale existem unidades habitacionais em fase de conclusão que, segundo informação do Secretário de Obras, serão entregues a beneficiários já cadastrados na prefeitura|

Figura 3 - Rol de informações de reconhecimento das áreas examinadas Fonte: Programa Acesso à Terra Urbanizada, 2015

E, com uma amostra mais específica, desta vez em relação ao Conjunto Projeto Crescer (área 1), verificou-se que certa organização fundiária, ao menos, já estava sendo encaminhada pela Prefeitura Municipal, sendo a área de domínio público (pertencente ao município) e utilizada há muito para fins de habitação.

Contudo, observe-se, pelo excerto tirado do respectivo formulário de caracterização de área, abaixo colacionado (Figura 4), que ainda subsistem certos obstáculos de infraestrutura e de condições ambientais, pois em muitas localidades o abastecimento de água é realizado por meio de carros-pipa, inexistindo rede de esgoto e pavimentação:

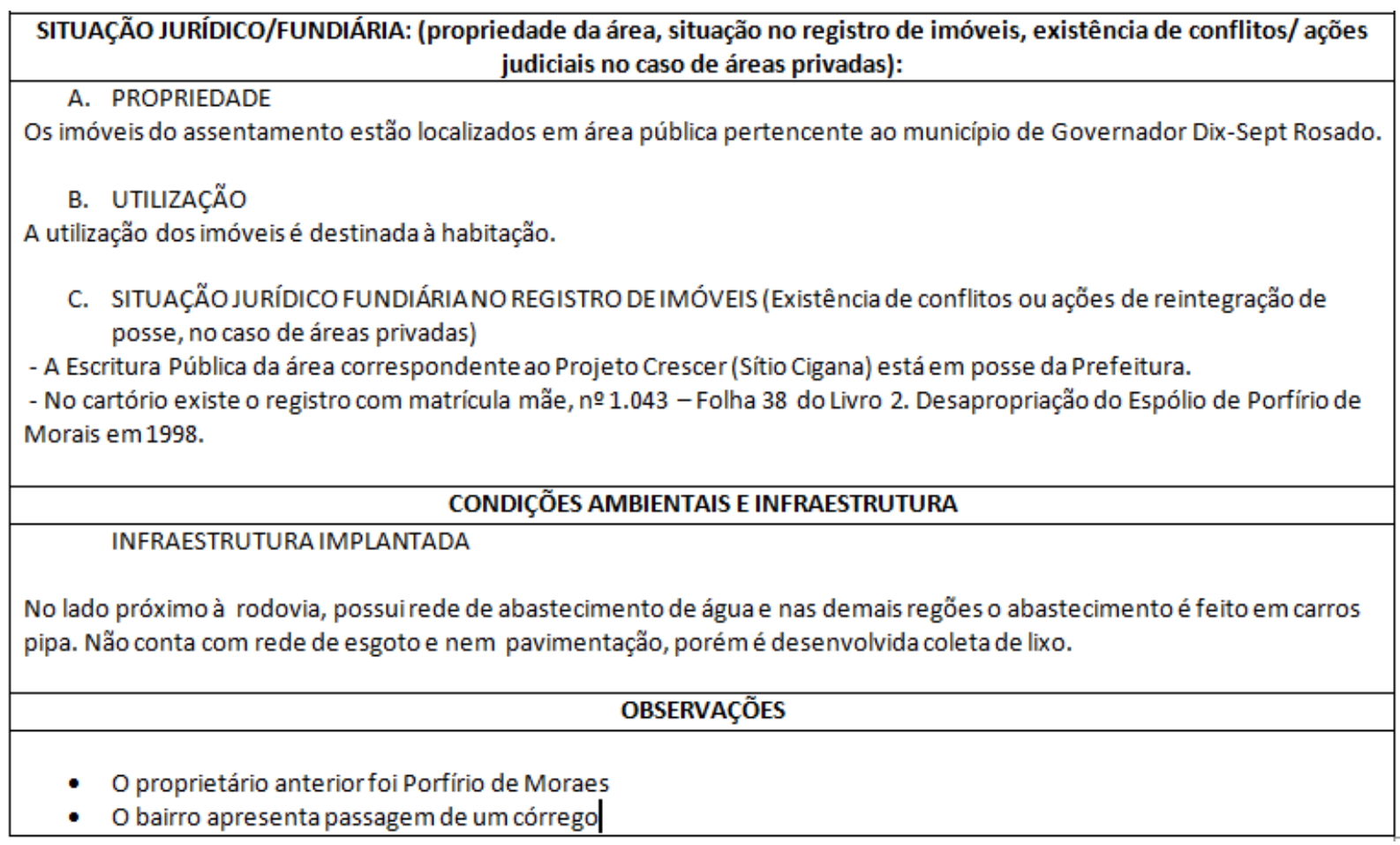

Figura 4 - Trecho do formulário de caracterização de área do assentamento Projeto Crescer Fonte: Programa Acesso à Terra Urbanizada, 2015 
Sobre a produção legislativa dos municípios participantes do projeto em comento é possível afirmar que, invariavelmente e até então, perdurava uma evidente e grave omissão. Os municípios que, ao contrário, em virtude de maior esforço despendido nesse sentido, merecem destaque positivo são Assu, Carnaubais, São Miguel e Tibau (ou Tibau do Norte):

\begin{tabular}{|c|c|c|c|c|c|c|c|c|c|c|}
\hline MUNICÍPIO & $\begin{array}{c}\text { LEI } \\
\text { V ORGÂNIC }\end{array}$ & $\begin{array}{l}\text { PLANO } \\
\text { DIRETOR }\end{array}$ & $\begin{array}{l}\text { CÓDIGO DE } \\
\text { POSTURA V }\end{array}$ & $\begin{array}{c}\text { CÓDIGO } \\
\text { TRIBUTÁRIO }\end{array}$ & CÓDIGO DE OBRA & $\begin{array}{l}\text { LEI DO PERIMETRO } \\
\text { URBANO }\end{array}$ & $\begin{array}{c}\text { LEI DE REG. } \\
\text { FUND. }\end{array}$ & $\begin{array}{c}\text { FUNDO } \\
\text { MUNICIPAL DF } \\
\text { HAR }\end{array}$ & $\begin{array}{c}\text { LEIDE } \\
\text { DOACÃAO DE } \\
\text { TERRENI }\end{array}$ & OUTRAS LEIS \\
\hline ASSÚ & POSSUI & $L C n=15 / 06$ & & LC ne 38/09 & LC ${ }^{2} 23 / 08$ & & & Lei no $247 / 07$ & POSSUI & $\begin{array}{l}\text { Lei de Zoneamento } \\
\text { Urbano }\end{array}$ \\
\hline CARNAUBAIS & POSSUI & & & Lein $16 / 97$ & Lein $16 / 97$ & Leinn 166/09 & & Lei no 18/2014 & Leine $87 / 04$ & $\begin{array}{c}\text { Lei de Implementação de } \\
\text { Construções de UH pelo } \\
\text { PSH (Lei n- 83/04) }\end{array}$ \\
\hline ENCANTO & POSSUI & & & $L C n=002 / 2012$ & & & & & & \\
\hline $\begin{array}{l}\text { GOVERNADOR DIX-SEPT } \\
\text { ROSADO }\end{array}$ & POSSUI & & & Lein $833 / 90$ & & Leinn 432/2011 & & Leinn 392/09 & Leine 412/07 & $\begin{array}{l}\text { Lei de Adesão ao PSH (ñ } \\
\text { 391/09) e Lei de Adesão } \\
\text { ao PMCMV (ñ 409/2010) }\end{array}$ \\
\hline Janduís & POSSUI & & & & & & & & & \\
\hline LUIS GOMES & POSSUI & & Lein 0 053/99 & Lein $067 / 01$ & Leinn $55 / 99$ & & & & & \\
\hline \multicolumn{11}{|l|}{ PAU DOS FERROS } \\
\hline PORTALEGRE & Leinn 02/2012 & & & & & Lein? 267/2012 & & & & \\
\hline SÃOMIGUEL & POSSUI & Leine 656/08 & Leinn 483/02 & Lein 0 476/02 & Lein= 483/02 & & & & & $\begin{array}{c}\text { LCn? 03/05 e Lein? } \\
\text { 09/2010 (que alterou o } \\
\text { Código Tributárí do } \\
\text { Município) } \\
\end{array}$ \\
\hline TIBAU DO NORTE & POSSUI & & Lein? 04/98 & Leinn 348/2013 & Lein $17 / 98$ & & Lein $0376 / 2014$ & Lein $287 / 2011$ & & \begin{tabular}{|c|} 
Lei no 346/2014 (Plano \\
Plurianual para 0 \\
quadriênio 2014 a 2017) \\
\end{tabular} \\
\hline VENHAVER & & & & Lein 1 17/97 & & & & & Lein 0 076/01 & \\
\hline
\end{tabular}

Figura 5 - Planilha de levantamento de instrumentos jurídicos

Fonte: Programa Acesso à Terra Urbanizada, 2015

Ao final, centenas de declarações de posse foram entregues aos moradores beneficiários da parceira supramencionada, dos quais citem-se as mais de quatrocentas e cinquenta concedidas tão somente para os moradores dos assentamentos irregulares em $\mathrm{Assu}^{5}$.

Sob outra perspectiva, é salutar apreciar tais resultados, reconhecidos no prazo de um ano (pois projeto inicial finalizado em 2016), com a devida cautela, levando-se em consideração todo o procedimento administrativo acima referenciado e veiculado pela derrogada Lei $\mathrm{n}^{\circ}$ $11.977 / 09$.

Há uma explicação razoável para a imediatidade de tais irrefutáveis préstimos provenientes da parceria entre a instituição de ensino e o Governo Federal. E tal se deve ao quadro mais ou menos uniforme quanto ao aspecto dominial.

\footnotetext{
5 Mais informações desse teor foram publicadas no site da Ufersa, na página oficial disponível em: $<$ https://assecom.ufersa.edu.br/2016/12/19/acesso-a-terra-urbanizada-da-ufersa-entrega-mais-de-450-titulos-amoradores-de-assu/>.
} 
Em outras palavras, a titularidade que, na maioria das áreas trabalhadas, era de natureza pública, facilitou a instrução de pedidos de CUEM ou CDRU ${ }^{6}$ diante da desnecessidade de diligências para intimar possíveis proprietários e, por consequência, o ato de concessão de título legitimador da posse foi mais célere por inexistir conflito fundiário.

O que sucedeu, na verdade, não foi uma supressão propriamente dita do procedimento de demarcação urbanística, mas a sua simplificação, principalmente devido ao emprego de auxílio externo e sistemático de estudo multidisciplinar oferecido pela Ufersa e financiado pelo MEC e pelo MCidades.

Tanto assim o é que, no assentamento São Luiz, por exemplo, localizado no município de São Miguel/RN, constatou-se a indispensabilidade do auto de demarcação urbanística (de responsabilidade do ente público competente) e de seu registro, de forma a propiciar, em seguida, a fase do projeto de regularização fundiária (SOUSA JÚNIOR, et al., 2015, p. 21).

Cabe, por ora, acompanhar os motivos pelos quais o Governo Federal entendeu por bem alterar a sua forma de processamento, através de uma medida provisória (convertida na Lei ${ }^{\circ}$ $13.465 / 17)$.

\section{A PERSPECTIVA DE EFETIVIDADE DO DIREITO À MORADIA}

\subsection{Motivação para a alteração do marco regulatório e possíveis consequências}

A Medida Provisória n 759 foi editada no findar do ano de 2016 e a Presidência da República, consoante permissão contida no art. 62 da CF/88, ao arguir relevância e urgência, substituiu a sistemática da regularização fundiária urbana de interesse social, analisada acima, então prevista na Lei $\mathrm{n}^{\circ} 11.977 / 09$.

Em sua Exposição de Motivos (n $\left.{ }^{\circ} 00020 / 16\right)^{7}$, o Ministério das Cidades apresentou a sua principal justificativa, ipsis litteris:

Em razão da vigência de diversas normas de hierarquia diferentes versando sobre a regularização fundiária, algumas delas versando de maneira contraditória sobre a mesma política, o cumprimento adequado do comando constitucional pertinente vem sendo cada vez mais mitigado, situação essa que levou o próprio Tribunal de Contas da União a determinar a suspensão liminar de alguns desses atos, inviabilizando o processo de titulações.

\footnotetext{
${ }^{6}$ Estas concessões, externadas por títulos de legitimação de posse, são denominadas, respectivamente, de Concessão de Uso Especial para fins de Moradia (MP n 2.220/01) e Concessão de Direito Real de Uso (DecretoLei $\mathrm{n}^{\mathrm{o}}$ 271/67).

7 Disponível no site: <http://www.planalto.gov.br/ccivil_03/_ato2015-2018/2016/Exm/Exm-MP\%2075916.pdf>.
} 
Com o fim de desburocratizar o procedimento, destacou-se que um novo marco legal, "para além de preencher lacunas deixadas pelo legislador, vem dinamizar e simplificar inclusive sob uma perspectiva registral - o processo da regularização fundiária urbana no País, permitindo que este efetivamente alcance os seus fins".

A mesma conclusão também advém da seguinte motivação: "A proposta normativa contempla procedimento administrativo orientado pela simplicidade e consensualidade." Destarte, os maiores objetivos da alteração do processo de regularização fundiária urbana (tanto de interesse social quanto a de interesse específico) foram o de uniformizá-lo e agilizá-lo.

Forçoso é, entretanto, analisar cautelosamente estas modificações, comparando-as com a normatização anterior, verificando se, de fato, houve o aperfeiçoamento daquele marco legal (de 2009) e formar, por conseguinte, uma conclusão favorável ou desfavorável acerca das possíveis consequências jurídicas e práticas a respeito da vigência da Lei n $n^{\circ} 13.465 / 17$, com a autoridade que a extensão realizada em função do Programa Acesso à Terra Urbanizada permite a esse estudo.

Inicialmente, a motivação baseada no próprio requisito de adoção de uma medida provisória, a saber, relevância e urgência, pode ser considerada frágil, pois estes conceitos possuem uma carga valorativa que depende de apreciação subjetiva e que, por isto, comportam certa fluidez de significado.

A fim de corrigir esse estado de incerteza, tão prejudicial ao sistema jurídico, ora oscilando pelo preenchimento daquele pressuposto previsto no caput do art. 62 (da CF/88), ora variando para a sua infragilidade, é fundamental utilizar um paralelo de interpretação com as circunstâncias contemporâneas do plano fático.

Em que pese ser incontestável a importância da regularização fundiária, observe-se que já vigorava, no ordenamento pátrio, um sistema até então coerente e uniforme, como foi exposto no tópico precedente, e não apenas como conjunto normativo por si só, mas principalmente em relação a todas as outras disposições extensíveis, tais como o Estatuto da Cidade e as políticas urbanas até então desenvolvidas.

Além disso, a aplicação do procedimento então vigente, tal qual foi verificado pelo Programa Acesso à Terra Urbanizada, por exemplo, gerou frutos significativos. Estes argumentos revelam, a priori, a impropriedade da edição de uma medida provisória, em especial sob o fundamento da urgência. 
Por outro lado, é de bom alvitre recordar e reconhecer que os requisitos de relevância e urgência comportam uma apreciação, pelo Poder Executivo, essencialmente discricionária (e, portanto, política), pautada pelos critérios de conveniência e oportunidade.

Na prática, e no que tange ao tema em comento, a Medida Provisória $n^{\circ}$ 759/16, instrumento normativo com força de lei, serviu para suspender a aplicação da Lei nº 11.977/09 para os novos projetos de regularização.

Quanto ao trâmite de processamento, a MPV no 759/16 não padece de inconstitucionalidade formal, tendo sido convertida na Lei $\mathrm{n}^{\circ}$ 13.465/17 em 12 de julho, isto é, dentro do prazo de 120 (cento e vinte) dias $^{8}$ estabelecidos pelo art. $62, \S 3^{\circ}$ da CF/88.

A primeira novidade é que a Lei $n^{\circ} 13.465 / 17$ traz objetivos e princípios bem elaborados, abrangentes e coesos; o destaque é a possibilidade de resolução dos conflitos fundiários de forma consensual e extrajudicial, a exemplo das previsões contidas no art. $21, \S \S 3^{\circ}$ e $4^{\circ}$ (respectivamente, o Poder Público terá a faculdade de, para ensejar a composição e afastar a oposição do proprietário, alterar o auto de demarcação ou utilizar qualquer outra medida, além de também ser-lhe facultado o emprego da arbitragem, caso a mediação não tenha sido bem sucedida) e no art. 34 e parágrafos (que prevê a criação, pelos Municípios ou destes em convênio com os Tribunais de Justiça, de câmaras de prevenção e resolução administrativa de conflitos. Saliente-se que a instauração do procedimento administrativo de composição também poderá ocorrer de forma coletiva).

Outra mudança foi a unificação do processo de concessão da licença urbanística e da licença ambiental, de responsabilidade do Município, com a chamada CRF (Certidão de Regularização Fundiária, art. 11, inciso V), documento este que poderá abranger desde logo a listagem de ocupantes beneficiários e que consiste em ato administrativo final de aprovação da regularização.

Causa estranheza, contudo, a redação do art. $11, \S 1^{\circ}$, pois: "Para fins da Reurb" os Municípios poderão dispensar as exigências relativas ao percentual e às dimensões de áreas destinadas ao uso público ou ao tamanho dos lotes regularizados, assim como a outros parâmetros urbanísticos e edilícios."

Dessa maneira, constata-se que o intento de desburocratizar o processo administrativo pode ter levado o legislador federal a desconsiderar os padrões locais de urbanização e,

\footnotetext{
${ }^{8} \mathrm{O}$ recesso do Poder Legislativo inicia-se em 23 de dezembro e se encerra em 01 de fevereiro, consoante redação do art. 57 da CF/88.

${ }^{9}$ Sigla utilizada pelo próprio legislador para indicar a regularização fundiária urbana.
} 
consequentemente, também os de natureza ambiental. Porém, tomando-se como evidência a prática já corriqueira nesse sentido, convém reconhecer que a nova disposição não implica, aprioristicamente, em desrespeito aos ditames regulatórios então consolidados pela administração local.

Na realidade, a interpretação desta norma requer maior cautela. Ocorre que o primeiro páragrafo do art. 11 revela uma solução viável sem desconsiderar, inclusive, a padronização urbanística.

Inicialmente, considere-se que o Município, poder administrativo local, detém poder discricionário, mesmo se não possuir corpo especializado - o que não impede a promoção de $\operatorname{convênios~}^{10}$, significando até mesmo uma alternativa financeiramente determinante, após ponderação sobre a gestão orçamentária -, para avaliar as condições de cada caso concreto.

Nesse sentido, o novo marco legal priorizou esse poder de decisão administrativa local a fim de viabilizar a regularização fundiária, afastando o que até então era um entrave para a sua conclusão e ressaltando a garantia do direito social à moradia digna e das condições de vida adequadas, objetivo expressamente previsto em seu art. 11, inciso VI.

De mais a mais, não seria verossímil afirmar que a legislação já vigente se afastou dos aspectos ambientais e urbanísticos, e exemplo disto é o conceito de regularização fundiária por ela apresentada, além do rol de documentos mínimos, elencados no art. 35, que deverão instruir o projeto de Reurb, tais como o estudo preliminar de desconformidade urbanística e ambiental, o projeto urbanístico, o estudo técnico para situação de risco, se for o caso, e estudo técnico ambiental.

Outrossim, é plausível seguir essa linha de pensamento conclusivo pela seguinte eventualidade: se a Reurb envolver área de risco ${ }^{11}$ que não possa ser eliminado ou corrigido pela Administração Pública, o ente promovente deverá realocar os ocupantes, priorizando, portanto, estes critérios urbanísticos e ambientais sem desconsiderar os fatores social e jurídico desse procedimento complexo.

Ainda, houve ampliação do rol de legitimados para requerer a instauração do procedimento administrativo. Agora os entes federativos também podem atuar nesse sentido de

\footnotetext{
${ }^{10}$ Ou outras medidas semelhantes (parcerias ou "instrumentos congêneres", como a lei aduz) com o Ministério das Cidades (art. 29).

11 Área de risco é a qualificação dada a determinada região exposta a desastres de grandes proporções, como desabamentos, incêndios e inundações.
} 
forma indireta, por meio de suas respectivas entidades. E foram acrescentados ao rol a Defensoria Pública e o Ministério Público.

Essa expressiva modificação importa em mais uma atribuição às defensorias públicas e dialoga com o Novo Código de Processo Civil ${ }^{12}$, que dispôs a respeito quanto às ações possessórias, envolvendo também o Ministério Público.

Outra inovação que permite concluir pelo aprimoramento do trâmite da regularização fundiária de interesse social é a uniformização dos diversos instrumentos pelos quais será possível concretizá-la. Nesse ponto, mais uma vez, é de se admitir que o novo marco legal é harmônico com as demais normas pertinentes ao tema, tais como o Código Civil, o Estatuto da Cidade, a Lei de Parcelamento e a Lei de Licitações.

A desburocratização do procedimento igualmente fica evidente pela união do registro do projeto de regularização com a constituição do direito real em um ato administrativo único, a critério do ente competente, quando a Reurb-S $\mathrm{S}^{13}$ se der sobre bem imóvel público.

Essa regra, na verdade, nada mais é que o reconhecimento de que, no regime precedente, aguardava-se apenas por uma formalização, que era a dependência de autorização legislativa municipal. Isso foi possível porque a desafetação e outras exigências previstas no art. 17, inciso I da Lei $n^{\circ}$ 8.666/93 passaram a ser dispensáveis para fins de promoção da regularização fundiária.

Do mesmo modo, contribuiu para essa facilitação o fato de a fase de demarcação urbanística ter se tornado uma faculdade, na medida em que, segundo o novo marco, não constituirá óbice à efetivação da regularização fundiária, já que não será mais condição para seu processamento.

Este ponto, todavia, não induz a qualquer desconfiança de que o legislador desconsiderou o que as políticas urbanas, locais e regionais definiram a respeito dos padrões mínimos de identificação, organização e parcelamento do solo. Afinal, como observado em outra oportunidade, a demarcação urbanística consiste no levantamento de dados da área dominada pela informalidade.

A explicação se deve, mais uma vez, à flexibilização do rigor procedimental, privilegiando a analise discricionária do Poder Público frente às circunstâncias apresentadas segundo cada caso concreto.

\footnotetext{
12 Art. 554, $\S 1^{\circ}$.

${ }^{13}$ Sigla para regularização fundiária urbana de interesse social.
} 
A capacidade de escolha de adoção da fase sob exame, e não a sua extinção, ademais, é plenamente coerente com a prática então adquirida com a sistemática estabelecida pela Lei $\mathrm{n}^{\circ}$ 11.977/09, notadamente no que pertine aos bens públicos, sendo desnecessária quando o ente responsável detém conhecimento sobre o núcleo urbano informal.

Dentre outras críticas negativas, de propaganda publicizada por diversos movimentos sociais, enfatize-se a de que o novo procedimento não reconheceria as chamadas ZEIS - Zonas Especiais de Interesse Social, isto é, "parcela de área urbana, instituída pelo plano diretor ou definida por outra lei municipal, destinada preponderantemente à população de baixa renda e sujeita a regras específicas de parcelamento, uso e ocupação do solo." (redação do art. $18, \S 1^{\circ}$ ).

Em outros termos, essa é a redação contida no novo marco legal, que sequer modificou o conceito já predominante pelo outro regime de regularização fundiária; a diferença crucial, no entanto, é que atualmente há a garantia de que a Reurb não mais ficará condicionada à existência das ZEIS.

Mais uma diferença entre os regimes ora comparados é que, enquanto naquele de 2009 a implementação do projeto de regularização não garantia a legitimação de posse, embora devesse o poder público assegurar o direito à moradia, a nova legislação determina que os ocupantes que não constem na listagem inicial tenham domínio adquirido por legitimação fundiária ${ }^{14}$ através de cadastramento complementar.

Até então a legitimação de posse, com a concessão de títulos como a CUEM e a CDRU, era realizada indistintamente para quaisquer bens, independentemente da natureza da titularidade. Mais que isso, como revelam Chaves e Rosenvald (2015, p. 64), "toda a trajetória da legitimação da posse no Direito brasileiro concerne apenas aos bens públicos."

Ocorre que esta situação configura séria contradição com a conhecida previsão normativa contida no Código Civil (art. 102), na Constituição Federal (art. 191, parágrafo único) e com o posicionamento de balizada doutrina, da qual, como exemplos, citem-se Maria Helena Diniz (2014, p. 182) e Celso Antônio Bandeira de Mello (2013, p. 932).

Com base nas considerações feitas anteriormente, sabe-se que a conversão do título de legitimação de posse em título de propriedade é, na verdade, o reconhecimento da consolidação da aquisição por usucapião.

\footnotetext{
${ }^{14}$ A legitimação fundiária é a formalização da conversão da legitimação de posse em direito de propriedade através da chamada usucapião administrativa ou extrajudicial.
} 
Logo, o questionamento a ser feito é justamente acerca da costumeira aplicação do instituto de legitimação de posse em áreas de domínio público. A Lei n 13.465/17 pôs um fim a essa controvérsia ao explicitar, no art. $25, \S 2^{\circ}$, que a legitimação de posse não pode ser aplicada em imóveis de titularidade do Poder Público.

E isto não implica em prejuízo à regularização fundiária de interesse social e, consequentemente, ao cumprimento do direito social à moradia, pois a autorização legislativa pode ser dispensada para os casos de doação ${ }^{15}$ de imóveis públicos, de acordo com descrição supra, acelerando e simplificando os mecanismos de regularização. Em verdade, aquela previsão veio garantir uma estabilidade nas relações jurídicas de cunho fundiário.

No mais, quanto às aquisições consolidadas anteriormente ao novo regime, permanece dúvida sobre a possibilidade de reconhecimento de direito adquirido, haja vista que a vedação atualmente acentuada já existia no ordenamento jurídico pátrio.

Contudo, como esta situação gera grave estado de incerteza e de insegurança jurídica, a somar a condição de hipossuficiência dos beneficiados, a aplicação do princípio da razoabilidade é uma solução adequada, cabendo à Administração Pública regulamentar a respeito, se assim entender necessário, reconhecendo o direito pretérito.

Por fim, todo o procedimento passa a ter uma estrutura mais simplicada, mas não menos complexa, configurando verdadeira revisão da antiga regulamentação, propiciada pela experiência então obtida desde 2009, com o aprimoramento dos institutos e a exclusão de entraves meramente formais.

Com amparo nas informações levantadas em extensão promovida pela Ufersa e no estudo acima no que concerne ao procedimento administrativo em si, é possível concluir que, quantos aos aspectos abordados, a Lei $\mathrm{n}^{\circ}$ 13.465/17, tanto em relação às suas consequências de natureza empírica quanto à sua compatibilidade com o ordenamento jurídico, não padece de inconstitucionalidade material, não afronta os outros marcos regulatórios nem as políticas urbanas desenvolvidas até então nos âmbitos estadual e municipal, sendo respeitadas, por sua vez, a complexidade do problema fundiário e a gestão democrática do ambiente urbano.

Com esse panorama favorável, ao qual é possível associar um prognóstico promissor, por dedução, tendo-se em conta o melhoramento do procedimento que já rendia bons frutos,

\footnotetext{
15 É típico contrato de liberalidade, o qual deve ser moldado às características próprias do Direito Público. Em outras palavras, a Lei $\mathrm{n}^{\circ}$ 8.666/93, em seu art. 17, inciso I, alínea $h$ determina que, para tanto, deve-se, obrigatoriamente, ter autorização legislativa, e, considerando os programas de regularização fundiária de interesse social, é possível que a licitação para a escolha do donatário seja dispensada.
} 
conclui-se que o direito social à moradia foi privilegiado pela Lei $\mathrm{n}^{\circ} 13.465 / 17$, em cotejo com os demais direitos relacionados, de forma que a perspectiva de efetividade desse direito aos cidadãos com perfil não abrangido pelos progamas de financiamento habitacional adotados pelas administrações federal, regionais e locais poderá ser demonstrada empiricamente.

\subsection{A importância do procedimento e a revisão da teoria da escolha pública (public choice)}

É primordial finalizar o estudo conectando-o com a defesa da regulação feita por Steven Croley, jurista norte-americano que revisou a teoria da escolha pública, de George Stigler.

Croley afirma que é um paradoxo que o sistema de regulação governamental possua tão pouca estima entre os cidadãos e, ao mesmo tempo, seja uma estratégia de propaganda eleitoral de sucesso. Segundo ele, um dos motivos pelos quais a regulação é tão criticada é a ignorância acerca da forma como ela funciona, já que é um conjunto complexo de procedimentos de natureza administrativa (2008, p. 03).

De acordo com a teoria da escolha pública, na dinâmica do processo de regulação predominam acordos escusos realizados entre grupos de interesses "especiais" - que necessitam de políticas que lhes favoreçam - e políticos, que, por sua vez, precisam de recursos para se elegerem e manterem suas posições de poder. Dessa forma, prevalece um sentimento pessimista sobre a boa governança e sobre a atuação administrativa do Estado.

Sob esse prisma, enquanto a regulação guiada pelos interesses especiais aloca grande parte dos privilégios públicos para setores mais abastados em detrimento da sociedade como um todo, a administração voltada para o interesse geral é aquela que resulta no aumento do bem-estar social.

Ainda, a regulação voltada para o interesse público não traz prejuízos; todavia, se o faz, pois de toda sorte transfere vantagens a um coletivo específico, é de forma a ocasionar menos dano possível para o restante da sociedade, pois gera benefícios em cadeia (CROLEY, 2008, p. $10-11)$.

E aqui se inserem as críticas e a não aceitação à lei em estudo pelos movimentos sociais e demais setores organizados da sociedade engajados com a problemática questão fundiária. Uma destas censuras diz respeito à flexibilização de desafetação do imóvel público, que antes dependia de autorização legislativa, consoante disposição da Lei de Licitações ( ${ }^{\circ}$ 8.666/93, art. 17, inciso I, alínea $h$ ). 
O receio é que com a nova legislação ocorra uma espécie de privatização dos bens públicos, priorizando-se a regularização de condomínios fechados e desconsiderando-se o fator social presente nas ocupações do solo.

Contudo, o fundamento dessa rejeição à nova sistemática trazida pela Lei no 13.465/17 foi refutado pelos argumentos acima expostos. Isto é, inicialmente, já havia uma prática consolidada de concessão de títulos de legitimação de posse mesmo para os imóveis públicos, o que implicava na aquisição do bem mediante usucapião, inclusive com o endosso do ente respectivo.

A vedação a este respeito veio pacificar esta celeuma e, por outro lado, é necessário sopesá-la com a flexibilização do rigor então existente para formalizar o procedimento de doação de bem público. E esta constatação em nada resulta em favorecimento aos beneficiados com o procedimento de regularização fundiária de interesse específico em detrimento daqueles que são mais dependentes do auxílio estatal, afinal, até o procedimento é diverso tendo em conta esse objetivo.

É nesse sentido que Steven Croley afirma que a teoria da escolha pública, além de não explicar o caráter geral dos procedimentos administrativos, induz que o processo não apenas gera favorecimento aos grandes grupos de interesses, mas também elimina toda a possibilidade de beneficiar os interesses gerais da sociedade (2008, p. 305).

Consequentemente, reconhecer o teor daquela crítica feita à Lei $\mathrm{n}^{\mathrm{o}}$ 13.465/17 como verdadeira e utilizar as suas inferências negativas para o todo o procedimento administrativo complexo sob exame é, contraditoriamente, desconsiderar também toda a prática percebida pela regulamentação anterior - a qual foi aprimorada -, mesmo sendo tão elogiada pelos setores que ora censuram o novo marco.

Steven Croley (2008, p. 305) traz conclusão na mesma linha desse raciocínio: “A teoria da escolha pública da regulação é uma abtração rica, mas é empiricamente pobre.” (tradução nossa).

O jurista norte-americano revela ainda que a maior justificativa para o governo administrativo é a correção da concentração do poder de mercado, a proteção dos direitos e das demais externalidades decorrentes da liberdade e da propriedade. Por outro lado, ele também destaca que a Administração Pública é ineficiente e contraprodutiva, ampliando, na verdade, as falhas do mercado ou dos demais campos de regulação em virtude da burocracia (2008, p. 14$15)$. 
Observe-se que a burocracia foi um dos principais motivos pelos quais a MPV $n^{\circ}$ 759/16 foi editada e o único que mais se adéqua como alegação para a alteração do procedimento voltado para o interesse social.

Logo, associar o novo procedimento, mais atual e harmônico com as experiências obtidas durante a vigência da Lei $n^{\circ}$ 11.977/09, à satisfação de meros interesses ditos especiais é reduzir a complexidade da regulamentação e do processo administrativo à generalidade de esquemas políticos de corrupção, de desvio de função e de favorecimentos ilícitos sem estimar as repercussões sociais positivas.

\section{CONSIDERAÇÕES FINAIS}

Realizadas todas estas ponderações a respeito da regularização fundiária de interesse social, focando-se precipuamente em elementos jurídicos que, integrantes de um processo complexo, configuram, ao final, o novo instituto jurídico denominado legitimação fundiária, chegou-se a um desfecho sobre os benefícios trazidos pela Lei $\mathrm{n}^{\mathrm{o}} 13.465 / 17$, com a modernização, suprimento de lacunas e aprimoramento da sistemática em cotejo com os demais marcos legais pertinentes.

Considerou-se que a regularização fundiária de interesse social deve ser pensada para o futuro, pois requer custos elevados e atuação de profissionais de vários campos de atuação, tais como o direito, a engenharia civil, a topografia, o serviço social e equipes de comunicação e integração de informações, revelando, então, toda uma necessidade estrutural de funcionamento racional e estratégico.

É indubitável, portanto, que a perspectiva de efetividade do direito à moradia pela nova sistemática de regularização fundiária urbana de interesse social é propícia ao crítico momento de elevada demanda habitacional; contudo, essa sequência de atos procedimentais exige cautela e planejamento racional porque, conforme o exposto, pode culminar em várias soluções, na medida em que seja construído, direta ou indiretamente, um caminho adequado de solução de conflitos fundiários (tanto que a Lei $\mathrm{n}^{\mathrm{o}}$ 13.465/17 privilegiou os métodos de mediação, conciliação e arbitragem).

Ainda que diversas apreciações condenatórias se interponham entre a Lei n ${ }^{\circ}$ 13.465/17 e a análise imparcial e experimental da regularização fundiária urbana de interesse social, foi revelado que, em consonância com as críticas realizadas por Steven Croley à teoria da escolha 
pública (ou public choice), por mais que possam existir lacunas que possibilitem favorecimentos em praticamente todos os setores da atuação administrativa, a estrutura procedimental de natureza complexa, base de investigação deste trabalho, tem gerado resultados notáveis para serem ignorados pelos teóricos ou pelos opositores das gestões políticas.

Demostrou-se, por fim, que a legitimação fundiária - mecanismo de reconhecimento da titulação de propriedade após o trâmite de regularização fundiária e o decurso de cinco anos da legitimação da posse - ou mesmo a flexibilização do processo de doação de bem imóvel público para os fins acima explicitados, segundo as diretrizes da regularização por interesse social descritas pelo novo marco regulatório, são meios altamente eficazes de efetividade do direito à moradia.

\section{REFERÊNCIAS}

ANTIQUEIRA, Moisés. Pátrio poder e poder estatal na Roma das XII tábuas. Revista Justiça e História. Rio Grande do Sul, Tribunal de Justiça, nº 13, vol. 07, ISSN 1677-065X. Disponível em: <https://www.tjrs.jus.br/export/poder_judiciario/historia/memorial_do_poder_judiciario /memorial_judiciario_gaucho/revista_justica_e_historia/issn_1677-065x/v7n13/PATRIO_PO DER_E_PODER_ESTATA_NA_ROMA_DAS_XII_TABUAS.pdf $>$. Acesso em: 10 junho 2017.

AZEVEDO, Aluísio. O Cortiço. $1^{\text {a }}$ Ed. São Paulo: Objetivo, 2008.

BANCO DE DADOS - CBIC. Déficit habitacional no Brasil. Câmara Brasileira da Indústria da Construção (CBIC), set. 2016. Disponível em: <http://www.cbicdados.com .br/menu/deficit-habitacional/deficit-habitacional-no-brasil>. Acesso em: 14 jun. 2017.

BLOCH, Marc. A Sociedade Feudal. $1^{\text {a }}$ ed. Lisboa: Edições 70, 2009, trad. Emanuel Lourenço Godinho.

BRASIL. Lei no 601, de 18 de setembro de 1850. Diário Oficial da União, 1850. Dispõe sobre as terras devolutados do Império. Disponível em: <http://www.planalto.gov.br/ccivil_03/Leis /L0601-1850.htm>. Acesso em: 24 dez. 2016.

Constituição Federal, de 5 de outubro de 1988. Diário Oficial da União. Brasília, 1988. Disponível em: <http://www.planalto.gov.br/ccivil_03/constituicao/ConstituicaoCo mpilado.htm>. Acesso em: 20 jan. 2017.

Lei no 13.465, de 11 de julho de 2017. Diário Oficial da União. Brasília, 2017. Dispõe sobre a regularização fundiária rural e urbana e dá outras providências. Disponível em: 
<http://www.planalto.gov.br/ccivil_03/_ato2015-2018/2017/Lei/L13465.htm>. Acesso em: 13 julho 2017.

COUlanges, Numa Denis Fustel de. A Cidade Antiga: estudo sobre o culto, o direito e as instituições da Grécia e de Roma. 11ª reimp. São Paulo: Martin Claret, 2016.

CROLEY, Steven P. Regulation and public interests: the possibility of good regulatory government. Princeton: Princeton University Press, 2008.

DINIZ, Maria Helena. Curso de Direito Civil: direito das coisas. 29ª ed. São Paulo: Saraiva, 2014, vol. 04.

FAUSTO, Bóris. História do Brasil. $2^{a}$ ed. São Paulo: editora da Universidade de São Paulo: Fundação do Desenvolvimento da Educação, 1995.

GOVERNO FEDERAL. Ipea. Estimativas do déficit habitacional brasileiro (2007-2011) por municípios (2010). Brasília: Nota Técnica $\mathrm{n}^{\mathbf{0}}$ 1, maio de 2013. Disponível em: <http://www.ipea.gov.br/portal/images/stories/PDFs/nota_tecnica/130517_notatecnicadirur01 .pdf >. Acesso em: 20 dez. 2016.

HESSE, Konrad. A Força Normativa da Constituição. $1^{\text {a }}$ ed. Porto Alegre: Sérgio Antônio Fabris Editor, 1991, trad. Gilmar Ferreira Mendes.

LOCKE, John. Dois Tratados sobre o Governo. $3^{\text {a }}$ ed. São Paulo: Martins Fontes, 2005, trad. Julio Fischer.

MAQUIAVEL, Nicolau. O Príncipe. $1^{\text {a }}$ Ed. São Paulo: Penguin-Companhia das Letras, 2010.

MAZZUOLI, Valério de Oliveira. Curso de Direito Internacional Público. $5^{\text {a }}$ ed. São Paulo: Revista dos Tribunais, 2011.

MELlO, Celso Antônio Bandeira de. Curso de Direito Administrativo. 30ª ed. São Paulo: Malheiros, 2013.

MENESES, Fabiane Ziolla. 2008, o ano da construção civil: indicadores do setor foram positivos e mostraram crescimento geral de $50 \%$ em relação a 2007. Gazeta do Povo, dezembro 2008. Disponível em: <http://www.gazetadopovo.com.br/especiais/retrospectiva/2008/2008-oano-da-construcao-civil-bcnhwjgxe0g2g63w6lhk03yvi>. Acesso em: 12 junho 2017.

PAR - PROGRAMA DE ARRENDAMENTO RESIDENCIAL. Alerj Debate. Rio de Janeiro: TV Alerj, 06 de dezembro de 2010. Programa de TV. Disponível em: <https://www.youtube.com/watch?v=0FhXoxGL5yk>. Acesso em: 15 dez. 2016.

PROGRAMA ACESSO À TERRA URBANIZADA. Meta 1: produtos, capacitação das equipes, trabalho social, cartografia básica, regularização da base imobiliária.

SARLET, I. W. O direito fundamental à moradia na constituição: algumas anotações a respeito de seu contexto, conteúdo e possível eficácia. Revista Eletrônica sobre a Reforma do Estado (RERE). Salvador, Instituto Brasileiro de Direito Público, no 20, dez. 2009. Disponível em: 
<http://www.direitodoestado.com/revista/RERE-20-DEZEMBRO-2009-INGO-

SARLET.pdf $>$. Acesso em: 10 janeiro 2017.

O estado social de direito, a proibição de retrocesso e a garantia fundamental de propriedade. Revista Eletrônica sobre a Reforma do Estado (RERE), Salvador, Instituto Brasileiro de Direito Público, $\mathrm{n}^{\circ}$ 09, março, abril, maio, 2007. Disponível em: <http://www.direitodoestado.com.br/rere.asp>. Acesso em 10 maio 2016.

SILVA, José Afonso. Curso de direito constitucional positivo. $28^{a}$ ed. São Paulo: Malheiros, 2007.

SOUSA JÚNIOR, Almir Mariano; CARVALHO, C. C. A.; LIMA, D. F.; SILVA, M. M. N. Análise jurídico-fundiária em cidades da mesorregião potiguar: apontamentos de instrumentos legais para a promoção da regularização fundiária de interesse social. Revista Monografias Ambientais - REMOA v. 15, $\mathrm{n}^{\circ}$ 01, jan-abr. 2015, p. 06-22.

Trabalho recebido em 17 de maio de 2020 Aceito em 15 de abril de 2021 